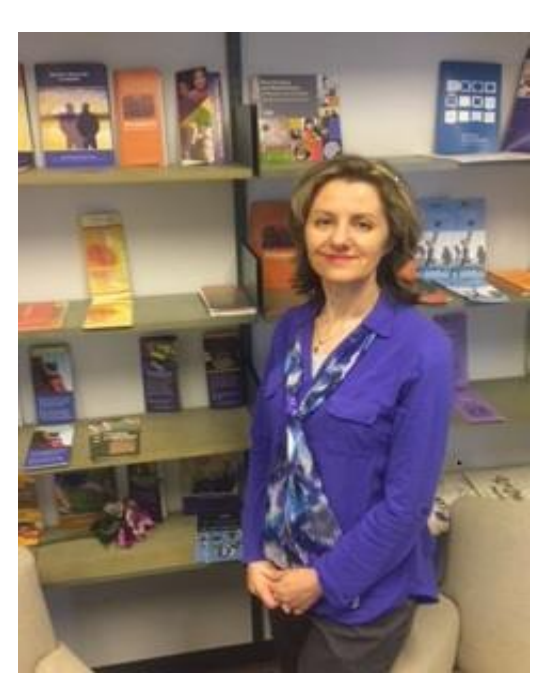

Dr. Nazilla Khanlou

\section{INYI Journal}

Editor: Nazilla Khanlou

Editorial Assistant: Luz Maria Vazquez

York University, HNES 3rd floor 4700 Keele Street

Toronto, ON, Canada, M3J 1P3

E-mail: owhchair@yorku.ca

Website:

http://nkhanlou.info.yorku.ca/

ISSN 1929-8471

\section{EDITORIAL}

As we head to the end of this year, and here in Toronto there is snow and cold weather with winter making its debut, we are grateful for the connections we have with INYI colleagues. Some of our colleagues are emerging scholars and to this end we are pleased to feature in this issue of the INYI Journal Ms. Esra Ari, a PhD Candidate in Sociology at Western University, Canada. In our last issue we had an article from Ms. Ari titled Multiculturalism: An antidote to racism or untouched inequalities.

In November of this year we held our $4^{\text {th }}$ Meighen Wright Maternal-Child Learning Institute. Dr. Attia Khan, who is a PhD candidate in the Faculty of Health at York University, has written an overview of this day and its presentations on page 8 . We also share with you an overview of a community event we held in July in connection with one of our studies on young adults with developmental disabilities, their families and service providers (page 9).

Our feature research article is from $\mathrm{Dr}$. Caroline Lenette at the University of New South Wales, Australia. In Kaja's story: The importance of narrative 'threads' as a qualitative analysis approach, Dr. Lenette applies narrative threads as a qualitative strategy in her research with young Australian refugee delegates. Among the strengths of this article are Dr. Lenette's explication of her positionality - an approach qualitative researchers apply to add rigor and transparency to their research - and the use of voice through Kaja's narrative to share findings. Dr. Lenette considers complexities of narrative threads in relation to refugee young people and as a method.

In May of this year I had the pleasure of presenting on immigration and mental health at the Migration Challenges in the Globalization Era event held at Instituto de Ciências da Saúde, Universidade Católica Portuguesa in Lisbon, Portugal.
In the next issue of INYI Journal we will feature the research work of faculty members at the Institute.

On behalf of Dr. Luz Maria Vazquez, Editorial Assistant to INYI Journal, and I, we wish you and your families a happy, healthy, and peaceful New Year.

\section{Nazilla Khanlou \\ Editor \\ York University}

